\title{
The population genetic consequences of range expansion : a re- view of pattern and process, and the value of oak gallwasps as a model system
}

Graham N. Stone ${ }^{1}$, Rachel J. Atkinson ${ }^{2}$, Gordon Brown ${ }^{1}$, Antonis Rokas ${ }^{1}$

1 University of Edinburgh Institute of Cell ,Animal and Population Biology, The Kings Buildings , West Mains Road, Edinburgh EH9 $3 \mathrm{JT}$

2 Department of Biology, University of Stirling , Stirling FK $4 L A$

\begin{abstract}
Biological invasions are a continuous feature of a non-equilibrium world, ever more so as a result of accidental and deliberate introductions by mankind. While many of these introductions are apparently harmless, others have significant consequences for organisms native to the invaded range , and entire communities may be affected. Here we provide a survey of common models of range expansion , and outline the consequences these models have for patterns in genetic diversity and population structure. We describe how patterns of genetic diversity at a range of markers can be used to infer invasion routes , and to reveal the roles of selection and drift in shaping population genetic patterns that accompany range expansion. We summarise a growing range of population genetic techniques that allow large changes in population size (bottlenecks and population expansions) to be inferred over a range of timescales. Finally, we illustrate some of the approaches described using data for a suite of invasions by oak gallwasps ( Hymenoptera , Cynipidae, Cynipini) in Europe. We show that over timescales ranging from $500 \sim 10000$ years, allele frequency data for polymorphic allozymes reveal (a) a consistent loss of genetic diversity along invasion routes, confirming the role of glacial refugia as centres of genetic diversity over these timescales, and ( b ) that populations in the invaded range are more subdivided genetically than those in the native range of each species. This spatial variation in population structure may be the result of variation in the patchiness of resources exploited by gallwasps, particularly host oak plants.
\end{abstract}

Key words : invasion, introduction, population genetics , gall wasps , Cynipidae

\section{Introduction}

The distributions of all organisms are not static in time and space, and range expansion on some temporal and spatial scale is a feature of the recent history of all species. A large body of theoretical and simulation-based literature shows that the processes underlying range expansion have important consequences for the genetic diversity and spatial structure of populations. This has resulted in turn in the development of methods which allow a range of aspects of the invasion process to be inferred using genetic data, including the origin of invaders, their pattern and sometimes mode of dispersal , and the direction and timescale of major changes in population size.

Study of the population genetics of biological inva- sions is important for a wide range of reasons. Pinpointing the origin of invaders can be important in discriminating among alternative colonisation scenarios, and is of obvious relevance in attempts to minimise the spread of pests (Davies et al. , 1999 ; Ibrahim et al. , 2000 ) , vectors of disease ( such as mosquito vectors of malaria ; Besansky et al. , 1997 ; Fonseca et al. , 2001), and species threatening local biodiversity (Geller et al. ,1997 ; Wilson et al. ,1999). Analysis of changes in population structure that accompany range expansion is essential to understanding the demography of invading populations, both for predicting future rates and patterns of spread, and for understanding why some invasions succeed while others fail ( Hard et al. , 1993 ; Hariston et al. , 1999). It can be important to know whether genetic changes associated 
with range expansion are the result of selection on specific loci ( for example, those associated with dispersal ability per se, or tolerance of aspects of the invaded habitat) (e. g. Daehler , 1998 ; Hard et al. , 1993 ; Lee , 1999 ; Weber \& Schmid , 1998 ) , or are generated principally by genetic drift (e. g Stone \& Sunnucks , 1993). Genetic markers can also reveal the extent to which invading organisms are interbreeding with native taxa, and so identifying threats due to introgression and, ultimately, genetic assimilation (Anttila et al. , 2000 ; Baumel et al. , 2001 ; Perry et al. $2001)$. Hybridisation of invading species with more benign taxa can also be a tool in the genetic management of aggressive invading species or races, such as the "Africanised" strains of the honeybee , Apis mellifera, in the Americas (Rinderer et al. , 1991 ; Sheppard et al. , 1991). Assessment of the timescales on which invasions generate geographic patterning in genetic diversity is important in assessment of conservation priorities, particularly for species in which a specific part of the range is threatened (Bos \& Sites , 2001 ; Mangel et al. , 1996 ; Pamilo \& Savolainen , 1999 ). Global warming is the greatest potential threat to populations at low latitudes, and for many species these same regions represent refugia during recent glacial cycles (Hewitt , 1996, 1999). Genetic analyses can reveal the extent to which such refugia remain centres of genetic diversity. Finally, a major application of the techniques discussed below has been to the complex issue of human radiations, reflecting both the abundance of genetic markers available for Homo sapiens, and an understandable interest in our own past ( Hammer et al. , 1998 ; Reich \& Goldstein , 1998 ; Reich et al. ,1999 ; Ruiz-Linares et al. ,1999 ; Thomas et al. ,2000).

Invasion processes operate over a vast range of spatial and temporal scales, and concern a range of biological entities, ranging from the dynamics of selfish genetic elements within genomes (Gimble , 2000 ; Quesneville \& Anxolabehere , 1998 ; Smith , 1998 ) to range changes by multicellular organisms over thousands of kilometres that take place over millenia. In this paper we concentrate on patterns in multicellular animals, but include reference to patterns ( such as selective sweeps) resulting from interactions between these organisms and pathogens. The paper is divided into two main sections. The first summarises existing models of range expansion, the predictions these make for patterns of genetic diversity and spatial structure, and illustrates application of analytical techniques designed to detect such patterns in real data. The second highlights pattern and process during range expansion in a specific group of insect invasions - the colonisation of northern Europe by oak-feeding gall wasps ( $\mathrm{Hy}-$ menoptera : Cynipidae) .

\section{Models of range expansion}

Models of range expansion ( and of population structure in general) can be divided into two types : island models , and stepping stone models (e.g. Gandon \& Rousset , 1999 ; Goodisman et al. , 1998 ; Irwin \& Taylor , 2000 ; Le Corre \& Kremer , 1998 ). The models have been widely used in analytical and simulation-based studies of population structure, and are applied either to a one-dimensional line of habitat patches or to a twodimensional array of habitat patches. Each patch can support a population, and once occupied can contribute colonists to other patches. Island and stepping stone models differ principally in the spatial arrangement of populations contributing colonists to a given patch.

(a) In island models, unoccupied patches are colonised independently by migrants from a single specified source population. In models involving multiple sources, colonists contributing to the establishment of a new population are taken at random from the entire set of populations.

(b) In stepping stone models, colonists arriving at a given patch are drawn from a limited neighbourhood around the patch. The probability that a population will contribute colonists to another patch is modelled as a function of distance between patches through the stepping stone network. Models vary from those in which colonisation is only from neighbouring patches , to those in which dispersal distances are normally distributed, and those with a leptokurtic distribution ( for normal and leptokurtic distributions of equal variance , a leptokurtic distribution is skewed to lower mean dispersal distances, but has a long tail encompassing rare, long-range dispersal events). The rare longrange dispersal events in leptokurtic models may have significant consequences for spatial patterns in genetic diversity established during invasion.

Island and neighbour-only stepping stone models 
represent two ends of a continuum of models. Although island models are assumed in a range of population genetic approximations ( for example, in the calculation of $N_{m}$ from estimates of $F_{\mathrm{st}}$ ) (Roderick, 1996), the assumptions of stepping-stone models involving a distribution of dispersal distances are generally regarded as more biologically appropriate. In general, the genetic consequences of range expansion are also far more pronounced and lasting in stepping stone models than in island models.

\section{Invasion models and spatial patterns in ge- netic diversity}

What determines how much of the genetic diversity present in an invasion source is present in populations at the limit of the invaded range ? For selectively neutral markers, both island and stepping-stone models predict the proportion of source genetic diversity that is present in an invaded patch to depend on (a) the founding population size ( $b$ ) the number of new colonists per generation, ( c ) the generation time of the species, and (d) the spatial distribution of patches that contribute those colonists (Austerlitz et al. , 1997 , 2000 ; Comps et al. , 2001 ; Le Corre \& Kremer , 1998$)$. For selectively neutral markers, the smaller the number of founders ( or of migrants between existing populations), the greater the potential for changes in gene frequencies by genetic drift. A major consequence of small founding population size is loss of genetic diversity ( also termed a genetic bottleneck or founder effect) (Ellstrand \& Elam , 1993 ; Nei et al. , 1975 ; Lacy , 1987 ; Barton \& Charlesworth , 1984 ).

Both island and stepping stone models of colonisation commonly predict loss of genetic diversity along an invasion route, although simulation studies have shown the loss of diversity to be most severe in stepping stone models ( Ibrahim et al. , 1996 ; Le Corre \& Kremer , $1998)$. This is because stepping stone colonisation involves repeated founder effects as the invasion front moves through an array of patches, and colonists are derived principally from neighbouring, recently founded populations which have themselves experienced genetic bottlenecks in the recent past (Le Corre \& Kremer , 1998 ).

Selection can also generate changes in diversity during range expansion — particularly where invasion has occurred over large distances and steep environ- mental gradients (Davis \& Shaw , 2001 ; Pamilo \& Savolainen , 1999). The most common pattern is a loss of diversity in the invaded range - either because a small proportion of the source variation is favoured in the invaded range, or because a selective agent (such as a parasite) that maintains genetic diversity in the source distribution is absent. Selection accompanying range expansion has been demonstrated for loci directly associated with dispersal (Florence et al. , 1982 ; Gu \& Danthanarayana , 1992) and for traits improving fitness in the invaded range (Daehler, 1998 ; Hard et al. , 1993 ; Lee , 1999 ; Weber \& Schmid , 1998 ).

It is important to appreciate that loss of diversity for selectively neutral markers can potential result from the effect of selection on other loci. First, when a selectively advantageous mutation spreads through a population to fixation ( a' selective sweep' ) , a particular selectively neutral variant at a closely linked locus may also be fixed ( a process termed hitch-hiking ; Maynard Smith \& Haigh , 1974). In addition to sweeps acting on nuclear loci, mitochondrial DNA can also be exposed to sweeps by selection acting on other maternally inherited entities. One example of this process is provided by work on the endoparasitic bacterium Wolbachia. Wolbachia strains infect a wide diversity of arthropods and nematodes, and cause a range of effects on the reproductive biology of their host (Werren , 1997 ). In some host taxa, infection results in cytoplasmic incompatibility, such that crosses between hosts infected with different Wolbachia strains are infertile ( Ballard et al. , 1996 ; Turelli et al. , 1992 ; Werren , 1997). Cytoplasmic incompatibility prevents any recombination between host mtDNA haplotypes and the Wolbachia strain present in the host germline, and the spread of a single dominant Wolbachia strain through the host population may lead to the establishment by hitch-hiking of a single dominant mitochondrial haplotype. There is increasing evidence for such an effect in many arthropods ( e.g. Turelli et al. ,1992 ; Ballard et $a l ., 1996)$. In many arthropods the impact of Wolbachia infection is unknown, and it is hard to predict the effect of infection on mitochondrial sequence divergence a priori. Low haplotype diversity in a species infected with Wolbachia could be the result of a selective sweep on maternally-inherited markers, or the result of demographic processes affecting the whole host genome ( such as a founder effect). In such cases, these alter- 
natives can be distinguished by comparing patterns in nuclear and mitochondrial markers (Rokas et al. 2002 ) : a Wolbachia selective sweep should affect only mitochondrial diversity, while a genetic bottleneck should also reduce diversity at nuclear markers.

Second, though mitochondrial haplotypes are commonly assumed to be selectively neutral , they may not be (Excoffier , 1990 , Ballard \& Kreitman , 1995). As a result, the population genetic consequences of range expansion should generally be regarded as the summation of selection and drift (Pamilo \& Savolainen $1999)$.

Finally, invaded range populations need not always have lower genetic diversity than source populations. Invasions may have multiple origins and occur over a range of timescales — such that the patterning seen in a given invaded area represents the summation of these multiple processes. This situation has been termed a metainvasion by Davies et al. (1999). Where alternative origins have diverged genetically, and both contribute adequate numbers of colonists to the same invaded range, it is possible for newly colonised areas to have higher genetic diversity than either origin (Slatkin , 1977 ; Comps et al. ,2001).

\section{Empirical patterns in genetic diversity}

Genetic diversity at polymorphic allozyme or microsatellite loci is commonly summarised by two statistics heterozygosity (the mean probability of a locus being heterozygous) and allelic diversity ( the mean number of alleles per locus). These indices are differentially affected by changes in population size, and the divergence of the relationship from predictions based on mutation-drift equilibrium forms the basis of a test for detection of population bottlenecks (described below).

Diversity in mitochondrial haplotype data is expressed either as haplotype diversity ( a measure equivalent to allelic diversity, but with an effective population size $1 / 4$ that of a nuclear marker), or as nucleotide diversity $(\Psi)$. Patterns accompanying range expansion depend on timescale, the evolutionary rate of the marker in question, the information content of the marker and the effective population size of the marker (Roderick 1996 ). Thus glacial refuges that have been separated without migrants for 10,000 years may be in the process of sorting ancestral polymorphism for allozyme loci ( high population size, low mutation rate), but have mutually discrete clades of mitochondrial haplo- types (1/4 of the population size for nuclear loci, higher mutation rate) - this effect is illustrated for gallwasps below. Populations that show little or no divergence in either of these markers may still be differentiated using sequence data for long, highly variable intron sequences (Davies et al. ,1999). Selection of a marker showing adequate variation among possible sources allows the origin of invading individuals to be identified using source-specific polymorphism ( e. g. Davies et al. , 1999 ; Demesure et al. , 1996 ; Dumolin-Lapègue et al. , 1997 ; Ferris et al. , 1995 ; Geller et al. , 1997 ; Konnert \& Bergmann , 1995 ; Matyas \& Sperisen , 2001). In Europe, colonisation routes for enough species have been identified in this way to allow major invasion routes to be identified (Hewitt , 1999 ; Taberlet et al. , 1998). An alternative for species showing low genetic diversity is to study genetic patterns in closely associated organisms, such as commensals or parasites : human range expansion has been reconstructed using genetic diversity in disease pathogens in the neotropics (Fisher et al. ,2001) and in commensal rats in Polynesia (Matisoo-Smith et al. , 1998 ) .

The vast majority of empirical studies of genetic variation in invading organisms show reduced diversity in the invaded range, particularly in cases of rare longrange anthropogenic dispersal (Broughton \& Grace, 1994 ; Daehler , 1998 ; Davies et al. , 1999 ; Tarr et al. , 1998 ; Tsutsui et al. , 2000 ; Villani et al. , 1994 ). The same general pattern is also generally seen in natural post-glacial range expansion, with lower diversity in apparently neutral markers at higher latitudes (Fig. 1a), whether in plants (Broyles, 1998 ; Lagerkrantz \& Ryman , 1990 ; Demesure et al. , 1996 ; Dumolin-Lapègue et al. , 1997 ; King \& Ferris , 1998 ; Tomaru et al. , 1997) , insects (Armbruster et al. , 1998 ; Hard et al. , 1993 ; Cooper et al. , 1995 ; Wilcock et al. ,2001) or vertebrates (Ball et al. , 1988 ; Merilä et al. , 1997 ; Sage \& Wolff, 1986 ). Exceptions to a general rule of loss of diversity with increasing latitude can be divided into three types : (a) species in which colonisation of lower latitude distributions occurred from high latitude refugia (Leonard et al. , 2000 ) (b ) species in which higher latitude ranges have been invaded from multiple refugia at lower latitudes (Fry \& Zink , 1998 ; Green et al. , 1996) , and (c) cases in which the colonization process has gener- 


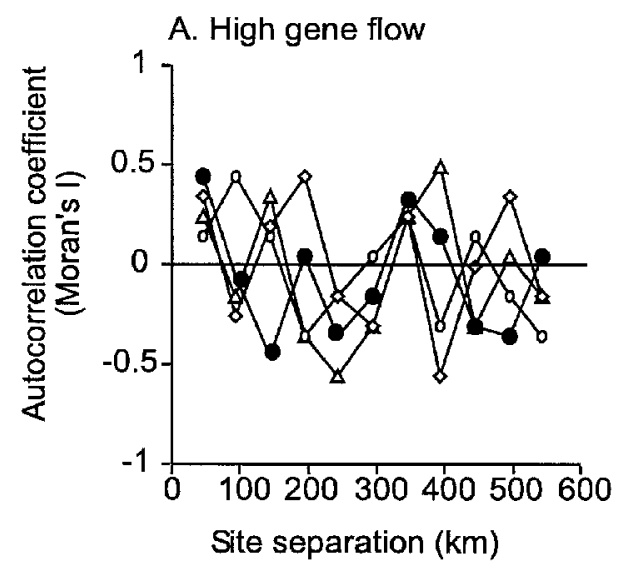

C. Directional migration

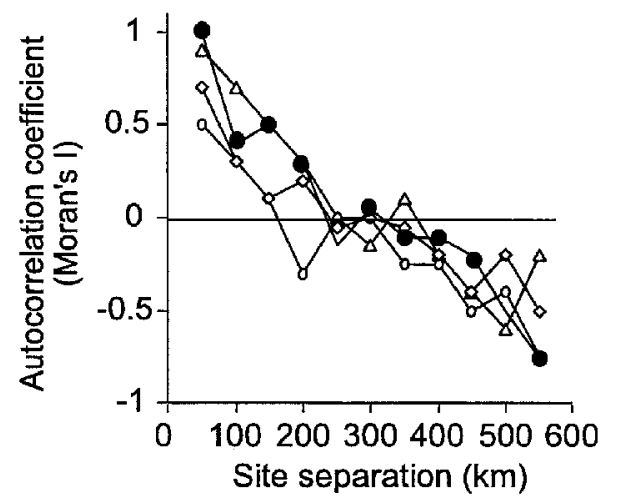

B. Isolation by distance

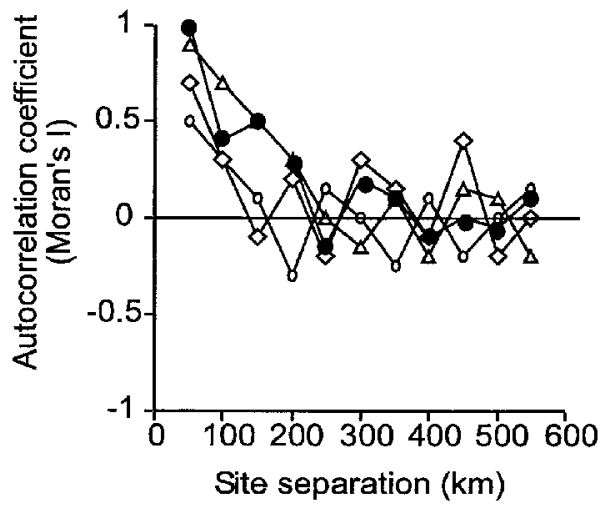

D. Selection on one locus

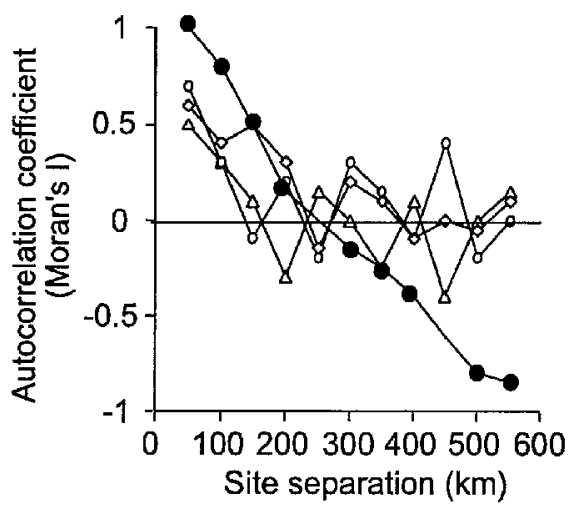

Fig. 1 Spatial autocorrelation patterns generated by different microevolutionary patterns. ( A) Panmixia , ( B) Isolation by distance , ( C ) Directional stepping stone migration with limited gene flow between populations, and (D) Clinal selection on a single locus. Figures are based on Sokal \& Jacquez (1991) and Sokal et al. (1997)

ated conflicting signals in allelic diversity and heterozygosity ( Comps et al. ,2001). In this last case , populations in the postglacial invaded range of a tree species , the European beech Fagus sylvatica, show loss of alleles (due to founder effects) but an increase in heterozygosity (due to genetic contributions from multiple sources) relative to refuge populations. The general persistence of declines in neutral genetic diversity with distance from glacial refugia over long timescales is most compatible with the predictions of the leptokurtic dispersal model described below.

Does such loss of neutral genetic diversity matter? The significance of genetic diversity as estimated by surveys of apparently selectively neutral markers remains a debated issue. Genetic diversity is the raw material of evolutionary change , including adaptation and speciation, so loss of diversity ( and particularly of alleles) during range expansion may have long-term implications for invading organisms. Populations in the invaded range of a species often show evidence of pop- ulation bottlenecks and of increased population fragmentation, which together result in genetic drift and diminished gene flow. As a result, low regional genetic diversity in the invaded range may conceal even lower effective diversity at the population level. Perhaps more importantly for invaders, these combined effects can prevent the spread of adaptive complexes outside their population of origin , thereby disrupting adaptation to novel selection pressures (Templeton et al. , 2001 ). The case of the argentine ant (Linepithema humile) shows that loss of diversity can result directly in major changes in species ecology ( Ross et al. , 1996 ; Tsutsui et al. , 2000). In its Argentinean native range, this species exists in small colonies, while in California the same species exists as supercolonies that come to dominate the local arthropod fauna. Analysis of colony genetic diversity in Argentina has shown that the extent of aggression between colonies correlates negatively with the genetic similarity between them. Surveys of colonies in California show very low genetic 
diversity, compatible with a severe founder effect for this invader. This low genetic diversity results in very high genetic similarity among colonies, and hence low or non-existent intercolony aggression, and the formation of supercolonies.

\section{Spatial patterns in gene frequencies resulting from range expansion}

Many studies have examined the consequences of range expansion on patterns of genetic subdivision between populations, and on the persistence of those patterns through time (Wade \& McCauley, 1988 ; Comps et al. ,2001 ; Stone \& Sunnucks , 1993 ). As with genetic diversity, patterning in spatial structure depends on the origin and frequency of migrants (Ibrahim et al. 1996 ; Nichols \& Hewitt , 1994 ; Slatkin , 1977 ; Wade \& McCauley , 1988). Rare, long-range dispersal, as encompassed in leptokurtic dispersal models, predicts both the establishment of stronger genetic subdivision in the invaded range than other models, and greater persistence of this substructuring through time ( Le Corre et al. , 1997 ; Hewitt , 1996 ; Ibrahim et al. , 1996 ; Nichols \& Hewitt, 1994 ). The persistence of substructuring has sometimes been attributed to the occupation of all available niche space by early colonists , such that later migrants are unable to establish themselves (Hewitt, 1996, 1999). Such resource limitation-based exclusion of colonists has yet to be demonstrated, and the nature of limiting resources remains little understood for the vast majority of organisms.

\section{Empirical patterns in population differentiation during range expansion}

Wade and McCauley ( 1988 ) suggested that for many invaders, higher rates of population extinction and lower rates of migration would result in greater genetic divergence between populations in the invaded range of a species. Some invading and introduced species do show this pattern (Stone \& Sunnucks, 1993 ; Tarr et al. , 1998). In others, however, long distance gene flow in the invaded range, and limited gene flow in localised refugia, generates the opposite trend (Comps et al. ,2001 ; Tomaru et al. , 1997) , and it remains impossible to make general predictions. The inability to draw a consensus is in part due to the rarity of studies with adequate sampling effort, in terms of spatial scale and number of polymorphic loci scored.

\section{Inference of population processes by analysis of}

\section{spatial patterns in genetic structure}

The modelling of invasion processes has led to the development of techniques designed to reveal range expansion from spatial patterning in genetic data. The two most widely applied approaches are (a) Mantel tests or spatial autocorrelation analysis of allele frequency data, and (b) nested clade analysis of the distribution of mitochondrial haplotypes, discussed in turn below. The former reveals patterns by comparing signatures across multiple loci, while the latter can reveal multiple effects through spatial patterning for a single marker. In both approaches, very high levels of gene flow among patches (effective panmixia) make distinction among alternate models of dispersal using genetic data either difficult or impossible. However, under a range of circumstances, island and stepping-stone models predict different spatial structures for selectively neutral markers. Pure island models predict neighbouring occupied patches to be no more similar genetically than expected by chance, because each patch is colonised independently from the source or from a spatially random set of sites. In contrast, stepping stone models predict neighbouring patches to be more similar than expected by chance. The relationship between similarity and the spatial separation between sites is also sensitive to the extent and direction of gene flow , producing differences that allow the identification of directional invasion processes. If gene flow occurs without directional bias across an array of patches, then stepping stone models predict the genetic similarity between patches to decline until it approaches that expected by chance. This signature is characteristic of isolation by distance , and is predicted for arrays of long-established populations with limited gene flow. However, if dispersal has a strong directional bias (as in invasions) , distant sites are also predicted to be significantly more different than expected by chance (Sokal et al. , 1997 ) .

Spatial autocorrelation analysis of allele frequencies

Spatial autocorrelation quantifies the similarity in allele frequency between two sites, relative to the similarity expected for the same trait were any two sites compared at random. The correlation is expressed as a normalised autocorrelation coefficient (such as Moran's I) , which ranges from 1 (maximum similarity) through 0 ( no more similar than expected at random) to -1 
(maximum difference). The pairwise comparisons for each allele are sorted into sets (distance classes) on the basis of the spatial separation between them , and the spatial structure in the data visualised by plotting the autocorrelation coefficient as a function of distance class. The resulting diagram is termed a correlogram. Extensive simulation studies show that a range of microevolutionary processes can be inferred by examining the shape of correlograms for individual alleles, and the congruence in pattern among alleles (Sokal \& Jacquez , 1991 ; Sokal \& Menozzi , 1982 ; Sokal et al. , 1997 ). Allele frequencies at a given locus may themselves be correlated (in the extreme, if there are only two alleles at a locus their frequencies must be inversely correlated), so a conservative result is obtained by using data from only a single allele per locus. For unlinked, selectively neutral loci , the stepping-stone scenarios above predict qualitatively similar patterns across loci, and consistent differences between models involving panmixia, isolation by distance, and directional migration ( Sokal \& Jacquez , 1991 ; Sokal \& Menozzi , 1982 ; Sokal et al. , 1997) (Fig. s 1a-c). Spatial autocorrelation also allows the identification of patterns in allele frequency resulting from selection : an allele showing clinal variation across a series of patches will show high similarity in neighbouring patches but differ more significantly in frequency than predicted by chance when the two ends of the cline are compared (Fig. 1d). This is a similar pattern to that expected for directional migration, except that here the pattern is expected only for the locus (or set of linked loci) under selection , and other unlinked and non-selected loci are expected to indicate processes affecting the genome as a whole. A consistent pattern across many loci can be generated in other scenarios unconnected with range expansion, such as the meeting of two genetically discrete taxa (including forms able to hybridize) at a contact zone. The possibility that invaders may be exchanging genes with native taxa should always be borne in mind when analysing genetic patterns.

\section{Nested Clade Analysis}

Spatial population processes can also be inferred using sequence-based methods. The most widely applied of these methods is Nested Clade Analysis ( Templeton 1998 ), which combines information on the spatial distribution of sequences ( particularly mitochondrial haplotypes ) and the phylogenetic relationships among them. The phylogeny is used to structure a series of nested analyses testing the null hypothesis of no geographic association among sequences. Where significant associations are detected, a hierarchical key allows discrimination among patterns generated by contiguous range expansion, long-distance colonisation , and isolation by distance (e. g. Crandall \& Templeton , 1999). A strength of this approach is that the nested structure of the analysis allows processes acting independently within different parts of phylogeny to be identified.

\section{Using genetic data to detect changes in pop- ulation size}

Range expansion processes are commonly associated both with initial founding by small numbers of colonists and, in some cases, subsequent dramatic increases in population size. Both of these processes are of interest in the study of invasions, and recent theoretical advances have resulted in tests that can be used to detect such demographic changes using population genetic data. As well as examining signatures of population founding, these tests have the potential to reveal geographic variation in the metapopulation behaviour of invaders. However, for acceptable statistical power the tests for both types of population change require data for many unlinked polymorphic loci, and the loss of diversity that commonly accompanies range expansion can limit their applicability. In practical terms, the existence of inadequate numbers of polymorphic markers limits the applicability of these approaches for many invading taxa.

\section{Identifying signatures of population bottlenecks}

In populations at genetic equilibrium (mutation-drift equilibrium), population genetic theory predicts a consistent relationship between the number of alleles at a locus (allelic diversity) and the heterozygosity observed at a locus (Nei et al. , 1975). Simulation and empirical studies have shown that genetic bottlenecks cause departures from this expectation; specifically, abrupt declines in population size cause a greater decrease in allelic diversity than in heterozygosity, and heterozygosity is only seriously reduced for very low population sizes ( Ellstrand \& Elam , 1993 ; Leberg , $1992)$. Population bottlenecks thus result in a heterozygosity excess at selectively neutral loci, i. e. the heterozygosity observed in a set of loci is greater than that expected from the number of alleles found in the sample under the assumption of mutation drift equilibri- 
um ( Cornuet \& Luikart, 1996). This bottleneck signature is transient, and is expected to disappear once mutation drift equilibrium is restored. Detection of such a heterozygosity excess at multiple loci forms the basis of a test for detection of bottlenecks ( "Bottleneck" , Cornuet \& Luikart , 1996 ) that has been applied to data for a range of invasion processes (e. g. Comps et al. ,2001 ; Jimenez et al. ,1999). A drawback of this test, and others that examine consensus in patterns across multiple loci, is that comparison of observed and expected genetic diversity requires polymorphic loci - and the bottlenecks associated with range expansion may reduce polymorphism to a level where the test has inadequate statistical power.

A recent simulation study (Luikart et al. , 1998) has shown the potential for demonstrating bottlenecks using an alternative approach, involving analysis of temporal shifts in the observed distribution of allele frequencies. Genetic bottlenecks are expected to cause rapid loss of rare alleles, and to increase the relative abundance of intermediate- and high-frequency alleles. Simulations suggest that tests based on this approach have higher statistical power for small numbers of polymorphic loci than those based on the detection of heterozygote excess (Luikart et al. , 1998), and so these tests may be a promising way forward for studies of taxa without extensive existing population genetic work. A challenge in this approach in that the test relies on accurately identifying pre- and post-bottleneck allele distributions. These are not easily identifiable in many ecological situations. In stepping-stone type invasions where the origin is known, however, the populations form a time series, and populations nearer the source can be regarded as hypothetical pre-bottleneck populations for populations further from the source. The expectations of mutation drift equilibrium are dependent to some extent on the model of allelic evolution assumed (Cornuet \& Luikart , 1996) , and the tests developed allow comparison of observed patterns with the predictions of both the infinite allele model ( usually applied to allozyme loci) and the stepwise mutation model more commonly assumed for microsatellites ( Goldstein \& Pollock, 1997).

Finally, an additional test recently developed for microsatellite data involves analysis of the mean ratio of the number of alleles to the range in allele size across a set of loci (Garza \& Williamson , 2001). This ratio falls when a population is reduced in size, and the magnitude of the decrease is correlated with the severi- ty and the duration of the reduction in population size.

\section{Identifying signatures of population growth}

The structure of gene genealogies at single loci is sensitive to the pattern of change in population size over time, such that populations of constant size produce genealogies with dramatically different structures to those for populations experiencing exponential growth ( Reich \& Goldstein , 1998 ; Reich et al. , 1999). At equilibrium in a population of constant size, genealogies for genes sampled in a population tend to have a single deep split (or node) and a variety of more shallow splits. In addition, genealogies for unlinked loci show considerable variation in the distribution of branch lengths between nodes (Reich \& Goldstein , 1998 ; Reich et al. , 1999). In contrast, exponential growth results in genealogies in which all branches are of similar length ( a' comb-like' genealogy) , in which lineages coalesce at or near the time at which exponential growth began ( Reich \& Goldstein , 1998 ; Reich et al. , 1999). In such a scenario, phylogenies for unlinked loci coalesce to a single common ancestor at around the same time depth. Thus both the variance in branch lengths for a given locus and the variance across loci are lower under exponential growth than for a population of constant size. If the timescale of the process is such that mutations can accumulate, rapid population growth generates expected distributions of sequence variation that differ from expectations assuming constant population size. This principle has been applied to analysis of sequence divergence in mtDNA (Merilä et al. , 1997 ; Zink et al. ,2000) and to expected distributions of allele sizes within and among microsatellite loci (Fisher et al. , 2001 ; Thomas et al. ,2000 ; Reich \& Goldstein , 1998 ; Reich et al. , 1999 ). The applicability of this test is limited to timescales over which mutations can accumulate over the markers in question, and even using the most rapidly evolving microsatellites, the tests commonly have low power for multicellular organisms on recent post-glacial timescales. The multi-locus tests also increase in power with increasing numbers and polymorphism of microsatellites, and this can also limit use of the test. These approaches have, however, been applied with considerable success to ancient changes (operating over timescales of hundreds of thousands of years) in human population size ( Reich \& Goldstein , 1998 ; Reich et al. , 1999) . 


\section{Oak gall wasps as a model system in inva- sion biology}

The summary above shows that aspects of the invasion process have been investigated in many species using a diversity of population genetic methods. It remains difficult , however , to identify which factors are correlated empirically with the direction and strength of genetic patterns associated with range expansion. The diversity of taxa and techniques applied often means that differences in variables of interest (such as the temporal or spatial scale of the invasion) are confounded with variation in the taxa studied or methods applied. The aim of the work described below was to use a consistent set of methods to generate population genetic analyses of range expansion for a group of closely related species , differing in variables of interest. We describe the biological background to the system, and illustrate how spatial patterns in genetic diversity can vary enormously even for closely-related species with similar ecologies and invasion histories.

\section{The oak gall wasp system}

Oak gall wasps ( Hymenoptera : Cynipidae, tribe Cynipini) are insects whose larvae develop within galls induced on oaks (members of the genus Quercus) and a small number of other host plants in the Fagaceae ( Stone et al. ,2002). Most species are cyclically parthenogenetic, and have a spring sexual generation and a summer/autumn asexual generation each year. Individual gall wasp species can only form galls on specific host oak taxa , and so have distributions intimately tied to those of their host plant. This dependence has generated gallwasp invasions on three temporal scales : (i) natural post glacial colonisation of higher latitudes from glacial refugia, (ii) natural colonisation of northern Europe over the last 500 years following human dispersal of an obligate host plant for members of the gallwasp genus Andricus, and (iii) very recent invasions of Japan and the United States by introduced gallwasp pests of cork oak (Quercus suber) (Bailey \& Stange , 1966 ) and chestnut (Castanea sp. ) (Moriya et al. , 1989 ; Payne , 1978 ). To date, population genetic analysis of range expansion have only been carried out over the first two timescales. Galls can be easily collected in the field and reared , making sampling of gallwasp populations and the detection of recent range expansions far easier than it is for many more cryptic organisms.
Post glacial and historical range expansions of European oak gallwasps

During the last ice age, oaks and gall wasps associated with them were restricted to three glacial refugia in Europe - the Iberian peninsular, southern Italy , and the Balkans ( Stone \& Sunnucks, 1993 ; Stone et al. $2001)$. Each of these refugia is bounded to the north by mountain ranges - the Pyrenees, Alps , Tartras and Carpathians, and with the retreat of the ice, only a limited diversity of oak species successfully escaped their glacial refugia and expanded their ranges far to the north. Much of northern Europe has only two oak species $-Q$. robur and $Q$. petraea. Fossil pollen data suggest that both of these oak species reached the current northern limits of their distribution ( which includes Britain ) approximately $6000 \sim 7000$ years ago (Huntley, 1990). A number of gall wasp species which attack these oaks, including sixteen species in the genus Andricus, also expanded their ranges northwards, and have probably been present in Britain for thousands of years.

Many other European species in the gallwasp genus Andricus have lifecycles that require two different oak taxa. For all of these species, the asexual generation develops in galls on hosts in the oak section Quercus (which includes $Q$. robur and $Q$. petraea) and a sexual generation that develops on oaks in the section Cerris (Stone et al. , 2002). In Europe, the section Cerris includes Quercus cerris, which is native to Italy and the Balkans, and Q. suber, which has disjunct races in Italy, the Iberian Peninsula and northwestern Africa (Stone et al. , 2001) (Fig. 2). For reasons that remain unclear, no section Cerris oaks were able to migrate northwards from their glacial refugia following retreat of the ice. As a result, gall wasps whose lifecycle involved section Cerris host plants also have natural distributions restricted to glacial refugia.

From the 15th century onwards, however, one section Cerris oak (the Turkey oak, Quercus cerris) became a popular ornamental tree throughout Europe , and has been dispersed beyond its native range by human trade. Q. cerris was introduced to Britain in the early 18th century, and is now self-seeding through much of its introduced range (Fig. 2). Introduction of Q. cerris has made it possible for gallwasps dependent on this oak to become invasive, and to date 7 species that alternate between this host and $Q$. petraea or $Q$. robur have become established in northern Europe 

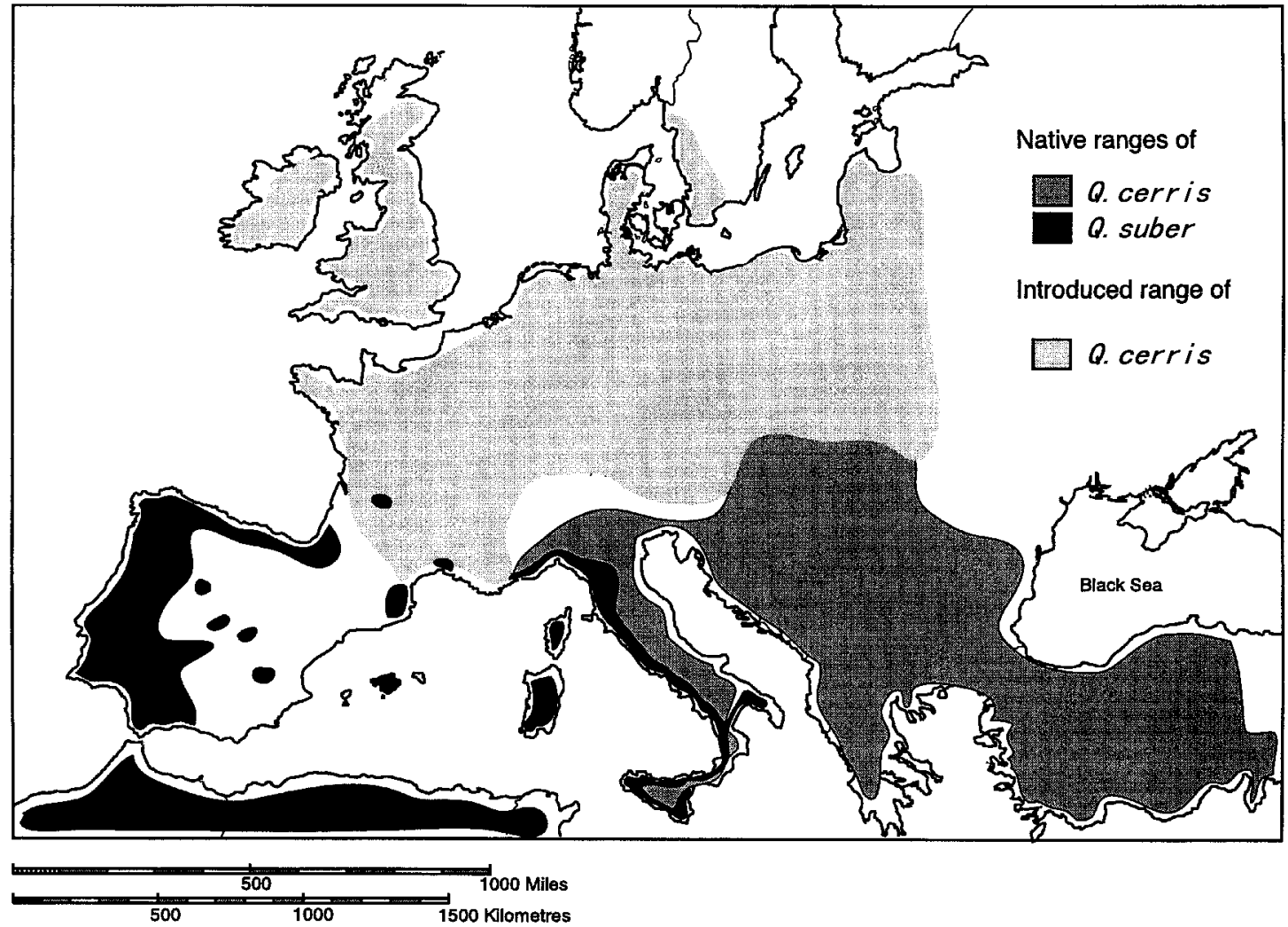

Fig. 2 The natural distributions of Quercus cerris and Q. suber, and the introduced range of Q. cerris (redrawn from Stone et al. , 2001 )

(Stone et al. ,2002). Three Andricus species reached Britain from the Balkans, apparently independently, between 1950 and 1970 ( $A$. ambiguus, A. lignicola and A. quercuscalicis ; Hails \& Crawley , 1991 ; Stone \& Sunnucks, 1993 ). Andricus quercuscalicis caused considerable public concern through spectacular population growth over the decades following its arrival. The same is true, though less dramatically so , for Andricus ambiguus and A. lignicola. Three more species reached Britain, also from central Europe, around the end of the last century ( $A$. aries, A. lucidus, Aphelonyx cerricola) and are currently expanding their distribution northwards from southeastern England.

An eighth species, Andricus kollari, has invaded much of northern Europe without direct human assistance. Unlike the previous Andricus species ,A. kollari is not naturally limited only to the distribution of $Q$. cerris , but is able to develop on a range of oak hosts in the section Cerris. In the extreme west of its range (north-west Africa, Spain and Portugal), the sexual generation host is $Q$. suber, in central-and eastern Europe east into Asia Minor the sexual generation host is Q. cerris, and in Syria, Lebanon and Israel the sexual generation host is probably $Q$. libani. Of these hosts, only $Q$. cerris is present in northern Europe, and is the only sexual generation host for invading populations. The colonisation of northern Europe by Andricus kollari could thus potentially have taken place either by individuals from central Europe (for which $Q$. cerris is the natural sexual generation host) or by individuals from the Iberian peninsular, following a host shift from $Q$. suber to $Q$. cerris.

European oak gall wasps provide opportunities to address a range of questions associated with range expansion.

(1) What are the consequences of recent, rapid range expansion for genetic diversity and population structure ? This question can be addressed for each of the invaders dependent on human dispersal of $Q$. cerris by analysing changes in diversity along the invasion route, and by comparing spatial patterns of genetic structure in refugial and invaded ranges. Comparison of patterns among species allows us to identify shared patterns (due to similar constraints acting on each range expansion process) from species-specific variation.

(2) How do patterns in recent invaders compare 
with patterns seen in species that induce galls on oaks that have been widely distributed in northern Europe for $8000 \sim 12000$ years? This comparison provides an indication of the timescale over which patterns established during recent range expansion can be expected to persist, and of the significance of glacial refugia as long term centres of genetic diversity. Here we present summary data for Cynips quercusfolii, a gallwasp whose lifecycle involves two generations on $Q$. petraea or $Q$. robur, and which is presumed to have been present throughout the range of these oaks in northern Europe for thousands of years.

(3) Are spatial patterns of genetic variation in gall wasps compatible with island or stepping stone models of range expansion?

(4) Are spatial patterns in allele frequencies compatible with the effects of selection or genetic drift?

The patterns described below, together with the population genetic methods involved, are described in detail in Stone \& Sunnucks (1993) and Stone et al. $(2001,2002)$.

\section{General patterns in genetic diversity}

Changes in genetic diversity along an invasion route are illustrated for Andricus quercuscalicis , a host alternating species originating in the Balkans ( Stone \& Sunnucks , 1993 ) (Fig. 3 ). Both mean heterozygosity and allelic diversity per locus show a dramatic decline along the invasion route (Fig. 3) , suggesting that severe founder effects have occurred during the invasion process in this species. The strong patterns in A. quercuscalicis raise the question of whether such trends in genetic diversity and population structure are shared among all recent invaders dependent on Quercus cerris, or the product of a specific aspect of the biology of this gallwasp species. Patterns in other recent invaders ( $A$. ambiguus and A. lignicola) are qualitatively similar, though difficulties in sampling these species leave the patterns for them far less well-resolved.

Andricus kollari is another host alternating species, with potential either to colonise northern Europe from the Iberian glacial refuge or from an eastern Balkan refuge. Analysis of the frequencies of refuge-specific private alleles, and of sequence variation in mitochondrial cytochrome b haplotypes shows that Iberian genotypes have been unable to exploit the human introduction of Quercus cerris (Fig. 4), and as for A. quercuscalicis the invaders in this species are derived from the Balkans (Stone et al. ,2001). Having established the origin of this species, it too shows loss of genetic diversity along the invasion route (Fig. 3 ). However, in contrast to Andricus quercuscalicis the loss of allelic diversity is not dramatic, providing far less indication of population bottlenecks during invasion by this species. Data for Cynips quercusfolii show patterns intermediate between those for A. kollari and A. quercuscalicis ( Fig. 5 ). This diversity in patterns among species makes it impossible to give any general conclusion on the relationship between time since the arrival of invaders and the extent to which genetic diversity is lost clearly more data are required. Nevertheless, these patterns do show that glacial refuges continue to be centres of genetic diversity long after post-glacial range expansion, and if preservation of genetic diversity is a priority in conservation efforts, such refugia should be protected.

\section{Spatial patterns in genetic structure : stepping stone or Island Model colonisation?}

Examination of patterns at individual loci in Andricus quercuscalicis shows that rare alleles are lost sequentially along the invasion route (Stone \& Sunnucks , 1993 ) , a pattern suggestive of stepping-stone colonisation. This interpretation is reinforced by spatial autocorrelation analysis, which across the whole invaded range of A. quercuscalicis showed parallel declines in genetic similarity with increasing site separation for almost all loci (the mean pattern across loci is shown in Fig. 6). This pattern gives a strong signature of directional stepping-stone migration followed by limited gene flow between populations. The same pattern, though weaker, is seen in A. kollari (Fig.6).

Comparison of patterns in the native and invaded ranges of A. quercuscalicis shows that while the native range shows a pattern characteristic of high gene flow (Fig. 7 ), there is a strong signature of directional stepping-stone migration followed by limited gene flow in the invaded range. Such a pattern could indicate the persistent population fragmentation predicted in the invaded range by leptokurtic dispersal models, and could also be due in part to the patchier distribution of $Q$. cerris outside its native range.

\section{Selection or drift?}

As discussed above , loss of genetic diversity and strong spatial structuring are compatible with scenarios involving either genetic drift or selection. The similarity of autocorrelograms for many unlinked loci in both $\mathrm{A}$. kol- 
A.

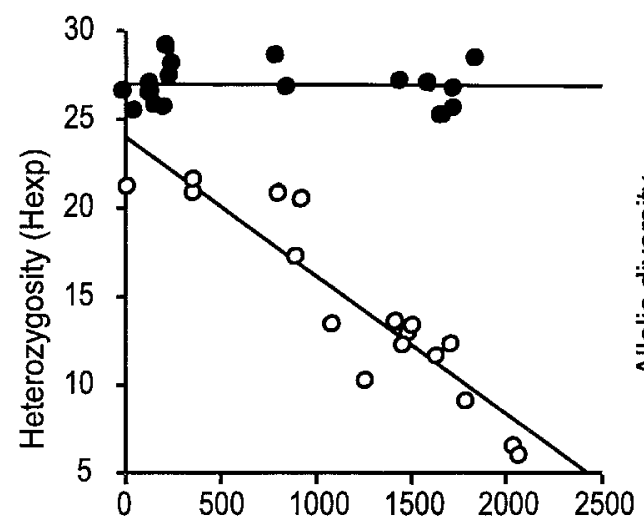

B.

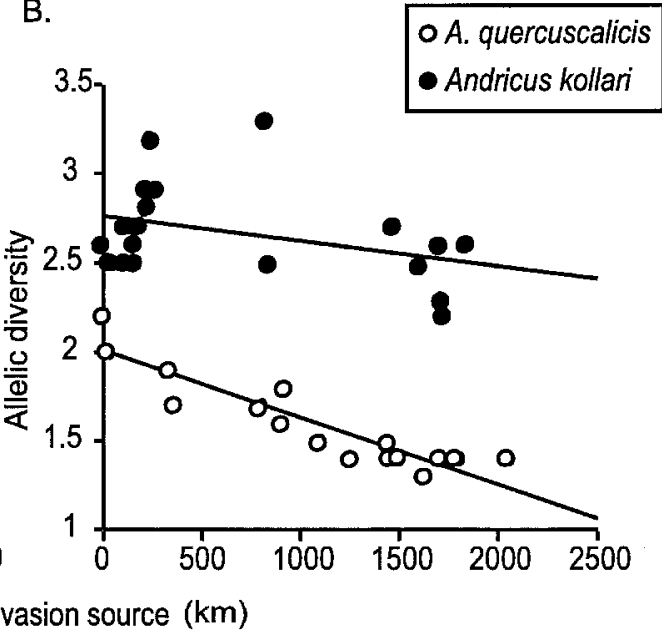

Fig. 3 Changes in genetic diversity with distance from invasion origins for the oak gall wasps Andricus quercuscalicis and A. kollari (A) Mean heterozygosity per locus , (B) Mean number of alleles per locus (allelic diversity). Data are from Stone \& Sunnucks (1993) and Stone et al. (2001).
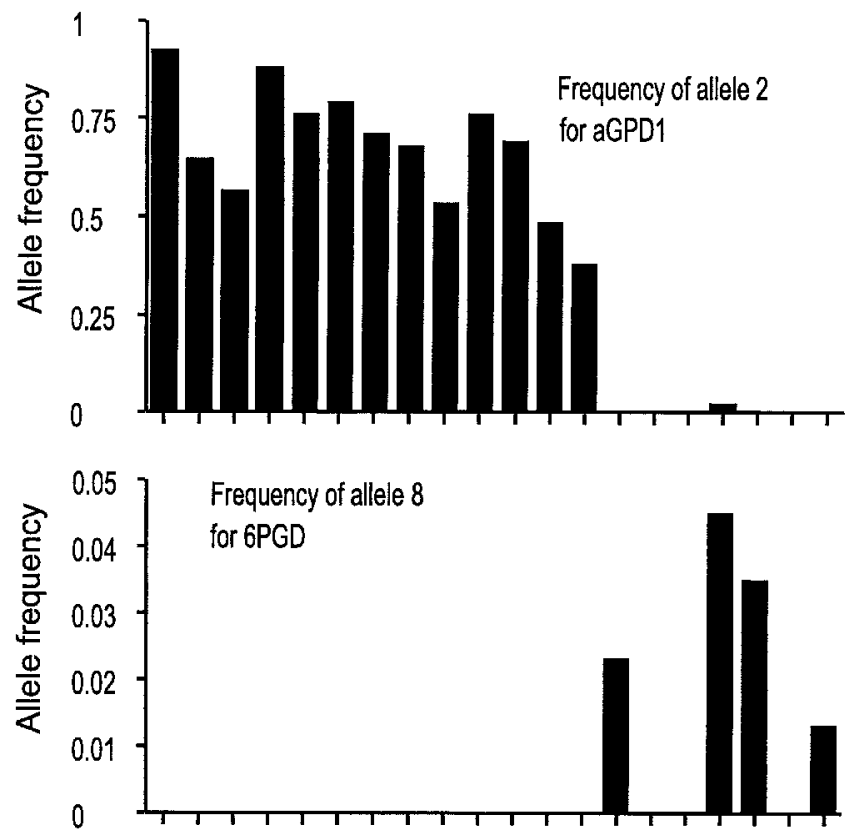

Sample locations

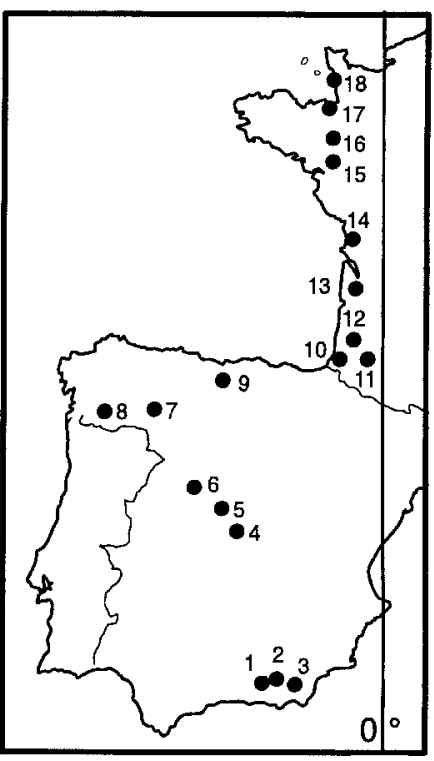

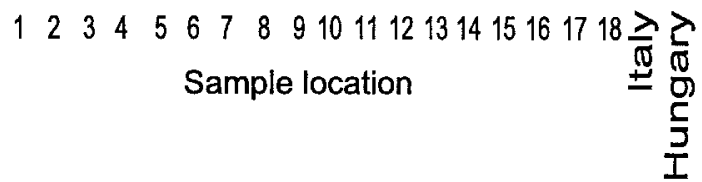

Fig. 4 The inability of Iberian genotypes of Andricus kollari to follow the human introduction of $Q$. cerris into northern Europe , as revealed by changes in the frequency of refuge-specific private allozyme alleles. The left-right arrangement of sites in the bar chart corresponds to the south-north ordering of samples sites in the map. The transition in Andricus kollari gene frequencies occurs at the northern limits of the natural distribution of the cork oak , Quercus suber, which is the sexual generation host for the Iberian race of Andricus kollari. Data are from Stone et al. (2001).

lari and A. quercuscalicis, however, is more indicative of a combination of genetic drift and directional migration than with a selective cause. Any selection-based scenario would have to explain why multiple loci should show clines on the same spatial scale. While this is possible , no similar empirical pattern has been demonstrated elsewhere. 

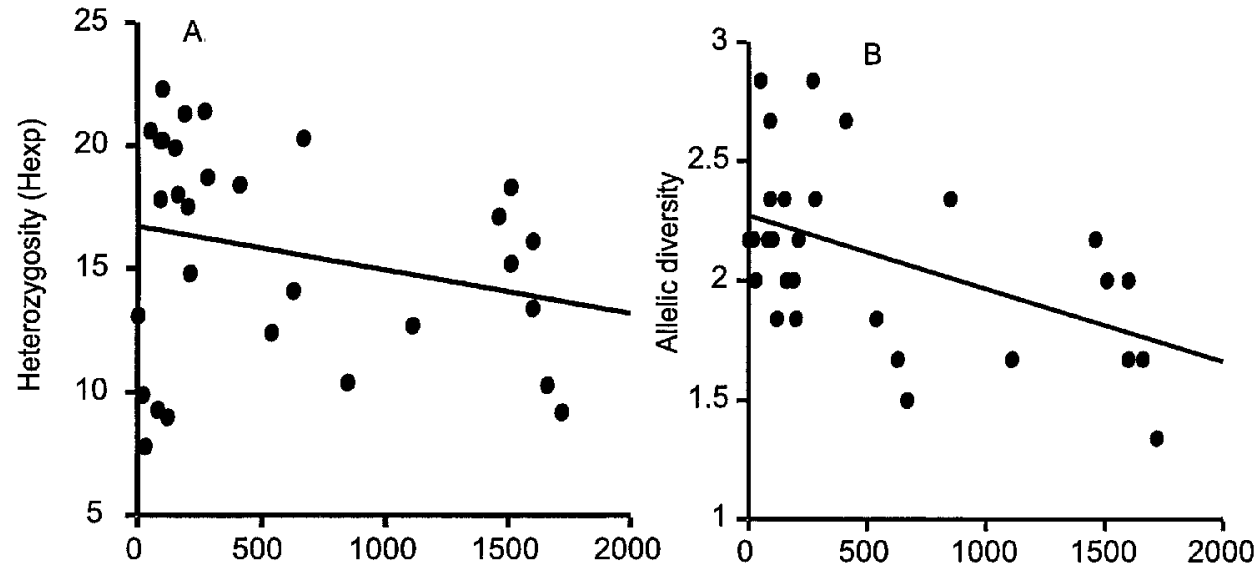

Distance from Invasion source $(\mathrm{km})$

Fig. 5 Changes in genetic diversity with distance from invasion origins for the oak gall wasp Cynips quercusfolii (A) Mean heterozygosity per locus, (B) Mean number of alleles per locus ( allelic diversity).

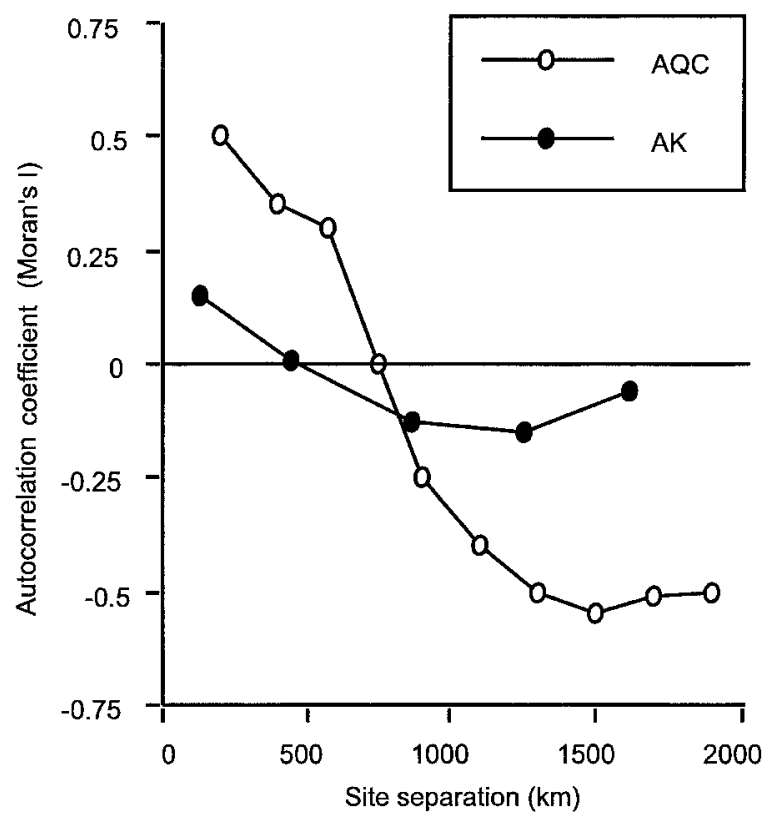

Fig. 6 Spatial autocorrelation of patterns in allele frequency through the naturally invaded ranges of Andricus quercuscalicis (AQC) and A. kollari (AK). The plots shown are mean values across correlograms generated for the same set of loci (GOT-s , GOT-m , PEP-b and PGM) for each species. Data are from Stone \& Sunnucks (1993) and Stone et al. , (2001).

\section{Variation in patterns across species}

A feature of this overview is that species invading over similar timescales (here, A. kollari and A. quercuscalicis ) may show dramatically different patterns. The differences suggest that an underlying dependence on the distribution of $Q$. cerris is not enough to produce similar spatial patterns in genetic diversity, and that other aspects of the ecology of these two species are important. Stronger spatial structuring and loss of diversity for A. quercuscalicis could result from higher rates of local extinction or population bottlenecks. Though little is known about bottom-up effects in gallwasp population dynamics (Stone et al. , 2002) , it is possible that the differences between these species may stem from differences in the host plant sites they require for gall induction. Galls of the asexual generation of A. kollari develop on buds, while those of $A$. quercuscalicis develop on acorns. While buds are not known to vary periodically in abundance, acorns certainly do , and cycling in acorn availability has been shown to drive the population size of A. quercuscalicis galls (Crawley \& Long , $1995)$. Although the effects of the dynamics of one generation on the effective population size of a gallwasp species remain unclear, it is possible that the patterns in A. quercuscalicis stem from a cycle in abundance driven by resource availability.

\section{Future directions}

The dramatic difference between patterns in these two species, which are similar in almost all aspects of their biology, highlights the need for detailed datasets for further species before general patterns can be identified. High levels of genetic diversity in European gallwasps suggests that population genetic analyses of the recent invasions of Japan and the United States by other gallwasp species would be rewarding. The possible impact of resource availability on genetic diversity and population structure in gall wasps highlights the need to link population genetics with population dynamics in 


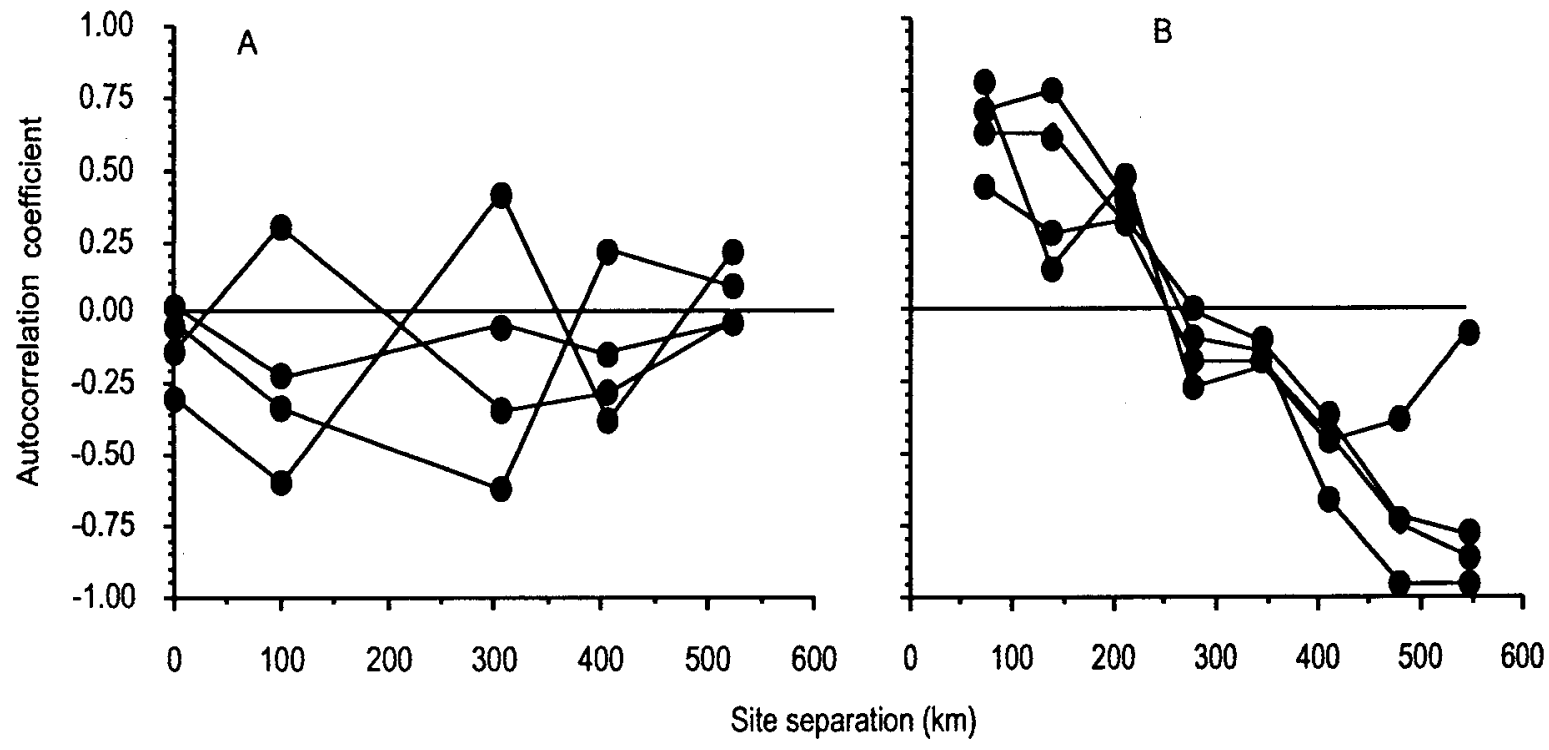

Fig. 7 A comparison of patterns of spatial genetic structure in Andricus quercuscalicis between (A) a set of Hungarian populations in the natural , refuge distribution of this species, and (B) a set of populations over the same spatial scale in Britain and Ireland. Data are for the alleles using data for the loci GOT-s , GOT-m , PEP-b and PGM from Stone \& Sunnucks (1993).

future work. More broadly, work on oak gall wasps has shown how the population genetics of an invading insect may be influenced by aspects of the biology of its host plants. With this in mind, it would be interesting to compare the patterns and process of postglacial range expansion in Asian oak cynipid species with patterns seen in Europe.

Acknowledgements The contribution of this paper was stimulated by the International Workshop on Biodiversity and Management for Alien Invasive Species, held in Zhuhai , China from May $22 \sim 23$, 2001. This meeting was convened by SEPA (the State Environmental Protection Administration of China), and the authors would like to thank SEPA, the Chinese Academy of Sciences, and the British Embassy in Beijing for making it possible for Dr. G. Stone to attend this meeting. We thank Dr. HAN Xing-Guo for his encouragement to publish this paper in Biodiversity Science.

We would like to thank all those who have helped with comments and ideas throughout the work leading to this review. We thank Dr. Gyuri Csóka, Rich Bailey, Mick Crawley, George Melika, Jose-Luis NievesAldrey and Karsten Schönrogge for their many thoughts and discussions on the subjects covered in this review. Most of all, we thank all those who have supported us in the field, particularly Gyuri , Ániko , Ági , Bence the bandit' Csóka , and the hungarian heros of forestry. This work was supported by the following grants to
GNS : a NERC EDGE program grant ( Gst/03/2035) and NERC grant (GR12847), a Small Ecological Research Grant from the British Ecological Society, and a Royal Society Research grant to GNS.

作者感谢 2001 年 5 月 22 23 日中国国家环保 总局主持召开的生物多样性与外来入侵物种管 理”国际研讨会。承蒙中国科学院,英国驻华使馆 提供的帮助，以及韩兴国博士的鼓励，使本文能在 《生物多样性》刊物发表。

\section{References}

Anttila C K, R A King, C Ferris, D R Ayres and D R Strong, 2000. Reciprocal hybrid formation of Spartina in San Francisco Bay. Molecular Ecology, 9: $765 \sim 770$

Armbruster P, W E Bradshaw and C M Holzapfel, 1998. Effects of postglacial range expansion on allozyme and quantitative genetic variation of the pitcher plant mosquito, Wyeomyia smithii. Evolution, 52: $1697 \sim 1704$

Austerlitz F, B Jung-Muller, B Godelle and P -H Gouyon, 1997. Evolution of coalescence times, genetic diversity and structure during colonisation. Theoretical Population Biology, 51: $148 \sim 164$

Austerlitz F, S Mariette, N Machon, P - H Gouyon and B Godelle, 2000. Effects of colonisation processes on genetic diversity: differences between annual plants and tree species

Bailey S F and L A Stange, 1966. The twig wasp of Cork OakIts biology and control. Journal of Economic Entomology, 59: $663 \sim 668$

Ball R M, S Freeman, F C James, E Bermingahm and J C Avise, 1988. Phylogeographic population structure of redwinged blackbirds assessed by mitochondrial DNA. Pro- 
ceedings of the National Academy of Sciences of the United States of America, 85: $1558 \sim 1562$

Ballard J W O and M Kreitman, 1995. Is mitochondrial DNA a strictly neutral marker? Trends in Ecology and Evolution, 10: $485 \sim 488$

Ballard J W O, J Hatzidakis, T L Karr and M Kreitman, 1996. Reduced variation in Drosophila simulans mitochondrial DNA. Genetics, 144: $1519 \sim 1528$

Barton N H and B Charlesworth, 1984. Genetic revolutions, founder effects and speciation. Annual Review of Ecology and Systematics, 5: $133 \sim 164$

Baumel A, M L Ainouche and J F Levasseur, 2001. Molecular investigations in populations of Spartina anglica C E Hubbard (Poaceae) invading coastal Brittany (France). Molecular Ecology, 10: $1689 \sim 1701$

Besansky N J, T Lehmann, G T Fahey, D Fontenille, L E O Braack, W A Hawley and F H Collins, 1997. Patterns of mitochondrial variation within and between African malaria vectors, Anopheles gambiae and A. arabiensis, suggest extensive gene flow. Genetics, 147: $1817 \sim 1828$

Bos D H and J W Sites, 2001. Phylogeography and conservation genetics of the Columbia spotted frog (Rana luteiventris; Amphibia, Ranidae). Molecular Ecology, 10: $1499 \sim 1523$

Broughton R E and J K Grace, 1994. Lack of mitochondrial DNA variation in an introduced population of the formosan subterranean termite (Isoptera, Rhinotermitidae). Sociobiology, 24: $121 \sim 126$

Broyles S B, 1998. Postglacial migration and the loss of allozyme variation in northern populations of Asclepias exaltata (Asclepiadaceae). American Journal of Botany, 85: 1091 $\sim 1097$

Comps B, D Gömöry, J Letouzey, B Thiébault and R J Petit, 2001. Diverging trends between heterozygosity and allelic richness during postglacial colonisation in the European beech. Genetics, 157: $389 \sim 397$

Cooper S J B, K M Ibrahim and G M Hewitt, 1995. Post-glacial expansion and genome subdivision in the European grasshopper Chorthippus parallelus. Molecular Ecology, 4: 49 60

Cornuet J M and G Luikart, 1996. Description and power analysis of two tests for detecting recent population bottlenecks from allele frequency data. Genetics, 144: $2001 \sim 2014$

Crandall K A and A R Templeton, 1999. The zoogeography and centers of origin of the crayfish subgenus Procericambarus (Decapoda: Cambaridae). Evolution, 53: $123 \sim 134$

Crawley M J and C R Long, 1995. Alternate bearing, predator satiation and seedling recruitment in Quercus robur. Journal of Ecology, 83: $683 \sim 696$

Daehler C C, 1998. Variation in self-fertility and the reproductive advantage of self-fertility for an invading plant (Spartina alterniflora). Evolutionary Ecology, 12: $553 \sim 568$

Davies N, F X Villablanca and G K Roderick, 1999. Bioinvasions of the medfly Ceratitis capitata: source estimation using DNA sequences at multiple intron loci. Genetics, 153: $351 \sim 360$

Davis M B and R G Shaw, 2001. Range shifts and adaptive responses to quaternary climate change. Science, 292: 673 679
Demesure B, B Comps and R J Petit, 1996. Chloroplast DNA phylogeography of the Common Beech, (Fagus sylvatica L. ) in Europe. Evolution, 50: $2515 \sim 2520$

Dumolin-Lapègue S, B Demesure, S Fineschi, V Le Corre and R J Petit, 1997. Phylogeographic structure of White oaks throughout the European continent. Genetics, 146: 1475 1487

Ellstrand N C and D R Elam, 1993. Population genetic consequences of small population size: implications for plant conservation. Annual Review of Ecology and Systematics, 24: $217 \sim 242$

Excoffier L, 1990. Evolution of human mitochondrial DNA: evidence for departure from a pure neutral model of populations at equilibrium. Journal of Molecular Evolution, 30: $125 \sim 139$

Ferris C, R P Oliver, A J Davy and G M Hewitt, 1995. Using chloroplast DNA to trace postglacial migration routes of oaks into Britain. Molecular Ecology, 4: $731 \sim 738$

Fisher M C, G L Koenig, T J White, G San-Blas, R Negroni, I G Alvarez, B Wanke and J W Taylor, 2001. Biogeographic range expansion into South America by Coccioides immitis mirrors New World patterns of human migration. Proceedings of the National Academy of Sciences of the United States of America, 98: $4558 \sim 4562$

Florence L Z, P C Johnson and J E Coster, 1982. Behavioral and genetic diversity during dispersal: analysis of a polymorphic esterase locus in southern pine beetle, Dendroctonus frontalis. Environmental Entomology, 1: $1014 \sim 1018$

Fonseca D M, S Campbell, W J Crans, M Mogi, I Miyagi, T Toma, M Bullians, T G Andreadis, R L Berry, B Pagac, M R Sardelis and R C Wilkerson, 2001. Aedes (Finlaya) japonicus (Diptera: Culicidae), a newly recognised mosquito in the United States: analyses of genetic variation in the United States and putative source populations. Journal of Medical Entomology, 38: $135 \sim 146$

Fry A J and R M Zink, 1998. Geographic analysis of nucleotide diversity and song sparrow (Aves: Emberizidae) population history. Molecular Ecology, 7: $1303 \sim 1313$

Gandon S and F Rousset, 1999. Evolution of stepping-stone dispersal rates. Proceedings of the Royal Society of London Series B - Biological Sciences, 266: $2507 \sim 2513$

Garza J C and E G Williamson, 2001. Detection of reduction in population size using data from microsatellite loci. Molecular Ecology, 10: $305 \sim 318$

Geller J B, E D Walton, E D Grosholz and G M Ruiz, 1997. Cryptic invasions of the crab Carcinus detected by molecular phylogeography. Molecular Ecology, 6: $901 \sim 906$

Gimble F S, 2000. Invasion of a multitude of genetic niches by mobile endonuclease genes. FEMS Microbiology Letters, 185: $99 \sim 107$

Goldstein D B and D D Pollock, 1997. Launching microsatellites: a review of mutation processes and methods of phylogenetic inference. Journal of Heredity, 88: $335 \sim 342$

Goodisman M A D, D D Shoemaker and M A Asmussen, 1998. Cytonuclear theory for haplodiploid species and X-inked genes. 2. Stepping-stone models of gene flow and application to a fire ant hybrid zone. Evolution, 52: $1423 \sim 1440$

Green D M, T F Sharbel, J Kearsley and H Kaiser, 1996. Post- 
glacial range fluctuation, genetic subdivision and speciation in the western North American spotted frog complex, Rana pretiosa. Evolution, 50: $374 \sim 390$

Gu H and W Danthanarayana, 1992. Quantitative genetic analysis of dispersal in Epiphyas postvittana 1. Genetic variation in flight capacity. Heredity, 68: $53 \sim 60$

Hails R S and M J Crawley, 1991. The population dynamics of an alien insect: Andricus quercuscalicis (Hymenoptera: Cynipidae). Journal of Animal Ecology, 60: $545 \sim 562$

Hammer M F, T Karafet, A Rasanayagam, E T Wood, T K Altheide, T Jenkins, R C Griffiths, A R Templeton and S L Zegura, 1998. Out of Africa and back again: nested clade analysis of human Y chromosome variation. Molecular Biology and Evolution, 15: $427 \sim 441$

Hard J J, W E Bradshaw and C M Holzapfel, 1993. Genetic coordination of demography and phenology in the pitcherplant mosquito, Wyeomyia smithii. Journal of Evolutionary Biology, 6: $707 \sim 723$

Hariston N G, L J Perry, A J Bohonak, M Q Fellows, C M Kearns and D R Engstrom, 1999. Population biology of a failed invasion: palaeolimnology of Daphnia exilis in upstate New York. Limnology and Oceanography, 44: $477 \sim 486$

Hewitt G M, 1996. Some genetic consequences of ice ages, and their role in divergence and speciation. Biological Journal of the Linnean Society, 58: $247 \sim 276$

Hewitt G M, 1999. Postglacial re-colonisation of European biota. Biological Journal of the Linnean Society, 68: $87 \sim 112$

Huntley B H, 1990. European vegetation history: palaeovegetation maps from pollen data - 13000 years BP to present. Journal of Quaternary Science, 5: $103 \sim 122$

Ibrahim K N, R A Nichols and G M Hewitt, 1996. Spatial patterns of genetic variation generated by different forms of dispersal during range expansion. Heredity, 77: $282 \sim 291$

Ibrahim K M, P Sourrouille and G M Hewitt, 2000. Are recession populations of the desert locust (Schistocerca gregaria) remnants of past swarms? Molecular Ecology, 9: $783 \sim 791$

Irwin A J and P D Taylor, 2000. Evolution of dispersal in a stepping stone population with overlapping generations. Theoretical Population Biology, 58: $321 \sim 328$

Jimenez P, D Agundez, R Alia and L Gil, 1999. Genetic variation in central and marginal populations of Quercus suber L. Silvae Genetica, 48: $278 \sim 284$

King R A and C Ferris, 1998. Chloroplast DNA phylogeography of Alnus glutinosa ( L.) Gaertn. Molecular Ecology, 7: $1151 \sim 1161$

Konnert M and F Bergmann, 1995. The geographical distribution of genetic variation of silver fir (Abies alba, Pinaceae) in relation to its migration history. Plant systematics and Evolution, 196: $19 \sim 30$

Lacy R C, 1987. Loss of genetic diversity from managed populations: interacting effects of drift, mutation, immigration, selection and population subdivision. Conservation Biology, 1: $143 \sim 158$

Lagerkrantz U and N Ryman, 1990. Genetic structure of Norway Spruce ( Picea abies) : concordance of morphological and allozymic variation. Evolution, 44: $38 \sim 53$

Leberg P L, 1992. Effects of population bottlenecks on genetic diversity as measured by allozyme electrophoresis. Evolu- tion, 46: $477 \sim 494$

Le Corre V, N Machon, R J Petit and A Kremer, 1997. Colonization with long distance seed dispersal and genetic structure of maternally inherited genes in forest trees: a simulation study. Genetical Research, 69: $117 \sim 125$

Le Corre V and A Kremer, 1998. Cumulative effects of founding events during colonisation on genetic diversity and differentiation in an island and stepping-stone model. Journal of Evolutionary Biology, 11: $495 \sim 512$

Lee C E, 1999. Rapid and repeated invasions of fresh water by the copepod Eurytemora affinis. Evolution, 53: 1423 1434

Leonard J A, R K Wayne and A Cooper, 2000. Population genetics of ice age brown bears. Proceedings of the National Academy of Sciences of the United States of America, 97: $1651 \sim 1654$

Luikart G, W B Sherwin, B M Steele and F W Allendorf, 1998. Usefulness of molecular markers for detecting population bottlenecks via monitoring genetic change. Molecular Ecology, 7: $963 \sim 974$

Mangel M, L M Talbot, G K Meffe, M T Agardy, D L Alverson, J Barlow, D B Botkin, G Budowski, T Clark, J Cooke, R H Crozier, P K Dayton, D L Elder, C W Fowler, S Funtowicz, J Giske, R J Hofman, S J Holt, S R Kellert, L A Kimball, D Ludwig, K Magnusson, B S Malayang, C Mann, E A Norse, S P Northridge, W F Perrin, C Perrings, R M Peterman, G B Rabb, H A Regier, J E Reynolds, K Sherman, M P Sissenwine, T D Smith, A Starfield, R J Taylor, M F Tillman, C Toft, J R Twiss, J Wilen and T P Young, 1996. Principles for the conservation of wild living resources. Ecological Applications, 6: $338 \sim 362$

Matisoo-Smith E, R M Roberts, G J Irwin, J S Allen, D Penny and D M Lambert, 1998. Patterns of prehistoric human mobility in Polynesia indicated by mtDNA from the Pacific rat. Proceedings of the National Academy of Sciences of the United States of America, 95: $15145 \sim 15150$

Matyas G and C Sperisen, 2001. Chloroplast DNA polymorphisms provide evidence for postglacial recolonisation of oaks (Quercus spp.) across the Swiss Alps. Theoretical and Applied Genetics, 102: $12 \sim 20$

Maynard Smith J and J Haigh, 1974. The hitch-hiking effect of a favorable gene. Genetical Research, 23: $23 \sim 35$

Merilä J, M Björklund and A J Baker, 1997. Historical demography and present day population structure of the Greenfinch, Carduelis chloris - an analysis of mtDNA control-region sequences. Evolution, 51: $946 \sim 956$

Moriya S, K Inoue, A Otake, M Shiga and M Mabuchi, 1989. Decline of the chestnut gall-wasp population, Dryocosmus kuriphilus Yasumatsu ( Hymenoptera: Cynipidae) after the establishment of Torymus Sinensis kamijo (Hymenoptera: Torymidae). Applied Entomology and Zoology, 24: 231 233

Nei M, T Maruyama and R Chakraborty, 1975. The bottleneck effect and genetic variability in populations. Evolution, 29: $1 \sim 10$

Nichols R A and G M Hewitt, 1994. The genetic consequences of long distance dispersal during colonisation. Heredity, 


\section{2: $312 \sim 317$}

Pamilo P and O Savolainen, 1999. Post-glacial colonization, drift, local selection and conservation value of populations: a northern perspective. Hereditas, 130: $229 \sim 238$

Payne J A, 1978. Oriental chestnut gallwasp: a new nut pest in north America. In: Macdonald W L, F C Cech, J Luchok and C Smith (ed.), Proceedings of the American Chestnut Symposium. $86 \sim 88$. West Virginia University Press, West Virginia, 428

Perry W L, J L Feder, G Dwyer and D M Lodge, 2001. Hybrid zone dynamics and species replacement between Orconectes crayfishes in a northern Wisconsin lake. Evolution, 55: $1153 \sim 1166$

Quesneville H and D Anxolabehere, 1998. Dynamics of transposable elements in metapopulations: a model of $\mathrm{P}$ element invasion in Drosophila. Theoretical Population Biology, 54: $175 \sim 193$

Reich D E, M W Feldman and D B Goldstein, 1999. Statistical properties of two tests that use multilocus datasets to detect population expansions. Molecular Biology and Evolution, 16: $453 \sim 466$

Reich D E and D B Goldstein, 1998. Genetic evidence for a palaeolithic human population expansion in Africa. Proceedings of the National Academy of Sciences of the United States of America, 95: $8119 \sim 8123$

Rinderer T E, J A Stelzer, B P Oldroyd, S M Buco and W L Rubink, 1991. Hybridization between European and africanised honeybees in the neotropical Yucatan peninsula. Science, 253: $309 \sim 311$

Roderick G K, 1996. Geographic structure of insect populations: gene flow, phylogeography, and their uses. Annual Review of Entomology, 41: $325 \sim 352$

Rokas A, R Atkinson, G Brown, S A West and G N Stone, 2002. Understanding patterns of genetic diversity in the oak gallwasp Biorhiza pallida: demographic history of a Wolbachia selective sweep? Heredity, 87: $294 \sim 305$

Ross K G, E L Vargo and L Keller, 1996. Social evolution in a new environment: the case of introduced fire ants. Proceedings of the National Academy of Sciences of the United States of America, 93: $3021 \sim 3025$

Ruiz-Linares A, D Ortiz-Barrientos, M Figueroa, N Mesa, J G Munera, G Bedoya, I D Velez, L F Garcia, A Perez-Lezaun, J Bertranpetit, M W Feldman and D B Goldstein, 1999. Microsatellites provide evidence for $\mathrm{Y}$ chromosome diversity among the founders of the New World. Proceedings of the National Academy of Sciences of the United States of America, 96: $6312 \sim 6317$

Sage R D and J O Wolff, 1986. Pleistocene glaciations, fluctuating ranges, and low genetic variability in a large mammal (Ovis dalli). Evolution, 40: $1092 \sim 1095$

Sheppard W S, T E Rinderer, J A Mazzoli, J A Stelzer and H Shimanuki, 1991. Gene flow between African- and European-derived honey bee populations in Argentina. Nature, 349: $782 \sim 784$

Slatkin M, 1977. Gene flow and genetic drift in a species subject to frequent local extinctions. Theoretical Population Biology, 12: $253 \sim 262$

Smith N G C, 1998. The dynamics of maternal effect selfish ge- netic elements. Journal of Theoretical Biology, 191: 173 180

Sokal R R and G M Jacquez, 1991. Testing inferences about microevolutionary processes by means of spatial autocorrelation analysis. Evolution, 5: $152 \sim 168$

Sokal R R and P Menozzi, 1982. Spatial autocorrelation of HLA frequencies in Europe support demic diffusion of early farmers. American Naturalist, 19: $1 \sim 17$

Sokal R R, N L Oden and B A Thomson, 1997. A simulation study of microevolutionary inferences by spatial autocorrelation analysis. Biological Journal of the Linnean Society, 60: $73 \sim 93$

Stone G N, R Atkinson, A Rokas, G Csóka and J-L NievesAldrey, 2001. Differential success in northwards range expansion between ecotypes of the marble gallwasp Andricus kollari: a tale of two lifecycles. Molecular Ecology, 10: $761 \sim 778$

Stone G N, K Schönrogge, R J Atkinson, D Bellido and J Pujade-Villar, 2002. The population biology of oak gall wasps ( Hymenoptera: Cynipidae). Annual Review of Entomology, 47: $633 \sim 668$

Stone G N and P J Sunnucks, 1993. The population genetics of an invasion through a patchy environment: the cynipid gallwasp Andricus quercuscalicis. Molecular Ecology, 2: 251 268

Taberlet P, L Fumagalli, A-G Wust-Saucy and J-F Cosson, 1998. Comparative phylogeography and postglacial colonisation routes in Europe. Molecular Ecology, 7: $453 \sim 464$

Tarr C L, S Conant and R C Fleischer, 1998. Founder events and variation at microsatellite loci in an insular passerine bird, the Laysan finch (Telespiza cantans). Molecular Ecology, 7: $719 \sim 731$

Templeton A R, R J Robertson, J Brisson and J Strasburg, 2001. Disrupting evolutionary processes: The effect of habitat fragmentation on collared lizards in the Missouri Ozarks. Proceedings of the National Academy of Sciences of the United States of America, 98: $5426 \sim 5432$

Templeton A R, 1998. Nested clade analyses of phylogeographic data: testing hypotheses about gene flow and population history. Molecular Ecology, 7: $381 \sim 397$

Thomas M G, T Parfitt, D A Weiss, K Skorecki, J F Wilson, M le Roux, N Bradman and D B Goldstein, 2000. Y chromosomes travelling south: the cohen modal haplotype and the origins of the Lemba - the "black jews of southern Africa”. American Journal of Human GeneticsI, 66: $674 \sim 686$

Tomaru N, T Mitsutsuji, M Takahashi, Y Tsumura, K Uchida and K Ohba, 1997. Genetic diversity in Fagus crenata (Japanese Beech) : influence of the distributional shift during the late Quaternary. Heredity, 78: $241 \sim 251$

Tsutsui N D, A V Suarez, D A Holway and T J Case, 2000. Reduced genetic variation and the success of an invasive species. Proceedings of the National Academy of Sciences of the United States of America, 97: 5948 5953

Turelli M, A A Hoffmann and W S McKechnie, 1992. Dynamics of cytoplasmic incompatibility and mtDNA variation in natural Drosophila simulans populations. Genetics, 132: $713 \sim 723$

Villani F, M Pigliucci and M Cherubini, 1994. Evolution of 
Castanea sativa Mill in Turkey and Europe. Genetical Research, 63: $109 \sim 116$

Wade J W and D E McCauley, 1988. Extinction and recolonization: their effects on the genetic differentiation of local populations. Evolution, 42: $995 \sim 1005$

Weber E and B Schmid, 1998. Latitudinal population differentiation in two species of Solidago (Asteraceae) introduced into Europe. American Journal of Botany, 85: $1110 \sim 1121$

Werren J H, 1997. Biology of Wolbachia. Annual Review of Entomology, 42: $587 \sim 609$

Wilcock H R, A G Hildrew and R A Nichols, 2001. Genetic differentiation of a European caddisfly: past and present gene flow among fragmented larval habitats. Molecular Ecology, 10: $1821 \sim 1834$

Wilson A B, K A Naish and E G Boulding, 1999. Multiple dispersal strategies of the invasive quagga mussel (Dreissena bugensis) as revealed by microsatellite analysis. Canadian Journal of Fisheries and Aquatic Sciences, 56: $2248 \sim 2261$

Zink R M, G F Barrowclough, J L Atwood and R C BlackwellRago, 2000. Genetics, taxonomy, and conservation of the threatened California gnatcatcher. Conservation Biology, 14: $1394 \sim 1405$

\section{分布区扩张的群体遗传学后果 :类型与过程 ,以栋瑤蜂为模型系统}

\section{Graham N. Stone ${ }^{1}$, Rachel J. Atkinson ${ }^{2}$, Gordon Brown ${ }^{1}$, Antonis Rokas ${ }^{1}$ \\ 1 University of Edinburgh Institute of Cell , Animal and Population Biology, The Kings Buildings ,} West Mains Road, Edinburgh EH9 3JT

2 Department of Biology, University of Stirling , Stirling FK 4LA

摘要: 生物入侵是不均衡世界的一个永恒话题, 尤其是当人类有意或无意地引入物种后。很多引入显然是无害的， 但另外一些则有着严重的后果，会给入侵地的生物以至于整个生物群落造成影响。本文总结了分布区扩张的常见 模式, 概述了它们对遗传多样性和种群结构式样所造成的影响。描述了如何根据以一批遗传标记所得到的遗传多 样性式样来推断入侵途径, 来揭示伴随扩张选择和漂变在形成种群遗传样式中的作用。本文对日益增多的群体遗 传学方法进行了总结, 这些技术可以用来在不同的时间尺度上推断种群规模所发生的巨大变化(瓶颈效应及种群 扩张)。最后, 我们以欧洲柇痑蜂 (膜翅目, 掼蜂科, 痋蜂族) 一系列入侵的数据为例对一些方法进行了说明。从 $500 \sim 10000$ 年的时间尺度上,多态的等位酶位点上等位基因频率的数据表明: 1) 遗传多样性沿入侵路线呈不断下 降的趋势, 支持了冰河期避难所作为遗传多样性中心的作用 2)入侵地区的种群与该物种原产地的种群相比, 遗传 上的分化更为强烈。这种种群结构在空间上的变异可能是被柇瘞蜂开发的资源尤其是柇树寄主在斑块上出现变 异的反映。

关键词：入侵,引入, 群体遗传学, 虫应, 䋣蜂科

中图分类号：Q346 文献标识码：A 文章编号 : 1005-0094(2002)01-0080-18 